\title{
On the Origin of the $\mathrm{CO}_{2}$ Climate Warming Fallacy
}

\author{
Jean-Paul Auffray \\ ex: Courant Institute of Mathematical Sciences, New York University, New York, USA \\ Email: jpauffray@yahoo.fr
}

Received 11 November 2015; accepted 1 December 2015; published 4 December 2015

Copyright (C) 2015 by author and Scientific Research Publishing Inc.

This work is licensed under the Creative Commons Attribution International License (CC BY).

http://creativecommons.org/licenses/by/4.0/

(c) ()

\begin{abstract}
We resurrect the 1896 paper in the frame of which the great Swedish physical chemist Svante August Arrhenius explains why what he called "aqueous vapour" and "carbonic acid" should be regarded as determining climate warming agents. We suggest that the designation "Green House Effect Gas" as applied to carbon dioxide should be officially banished from the climate vocabulary as being misleading.
\end{abstract}

\section{Keywords}

Fourier, Arrhenius, COP21, CMP11, Quantum Physics, $\mathrm{CO}_{2}, \mathrm{H}_{2} \mathrm{O}$

\section{Introduction}

It all began for real in April 1896, four years before the invention of Quantum Physics (QP), when the prestigious British scientific journal Philosophical Magazine and Journal of Science published a paper written by the great Swedish physical chemist Svante August Arrhenius (1859-1927) under the title "On the Influence of Carbonic Acid in the Air upon the Temperature of the Ground" [1]. The term "Carbonic acid" used in this title refers to the compound which corresponds to the chemical formula $\mathrm{H}_{2} \mathrm{CO}_{3}$, equivalently written as $\mathrm{OC}(\mathrm{OH})_{2}$ to reflect better the geometric structure of its molecule (Figure 1). This acid obtains when carbon dioxide, the (in)famous climate warming $\mathrm{CO}_{2}$, is dissolved in water as is the case for example in our carbonated soda drinks. In his paper, the great Arrhenius defined the erroneous concepts and established the fallacious vocabulary that some world cli-<smiles>O=C(O)O</smiles>

Figure 1. The carbonic acid molecule. https://upload.wikimedia.org/wikipedia/commons/thumb/c/c4/Carbonic-acid-2D.svg/150px-Carbonic-acid-2D.svg.png. 
mate experts still use today when they refer to climate warming.

\section{Against Strong Opposition}

Lecturer at the Stockholms Högskola, now Stockholm University, Svante Arrhenius was promoted to professor of physics in 1895. He was elected a member of the Royal Swedish Academy of Sciences soon after (against strong opposition) and became involved in setting up the Nobel Institutes and the Nobel Prizes. In 1903 he became the first Swede to be awarded the Nobel Prize for Chemistry. He used his positions to arrange prizes for his friends, the Dutch chemist Jacobus van ' $t$ Hoff, first laureate of the Nobel Prize for Chemistry in 1901, the German chemist Wilhelm Ostwald, Nobel laureate for Chemistry in 1909, and the American Theodore Richards, Nobel laureate for Chemistry in 1914. Our hero (reportedly) attempted at the same time to deny Nobel Prizes to his enemies-Paul Ehrlich, Walther Nernst, Dimitri Mendeleev... At a time when his good friend Wilhelm Ostwald influenced through his writings young Albert Einstein in favor of the concept of "Absolute measurements" [2], Arrhenius sought to establish his own predominance in the world of science by providing a documented answer to this probing question: "Is the mean temperature of the ground in any way influenced by the presence of heat-absorbing gases in the atmosphere?" [1].

Heat-absorbing gases... still a gentle appellation. Worse is to come.

\section{Words}

On the tenth line of this famous paper, Arrhenius refers to the significant essay published in 1827 by the outstanding French mathematician and physicist Joseph Fourier who, said Arrhenius, "maintained that the atmosphere acts like the glass of a hothouse...”.

STOP!

Acts like the glass of a hothouse...?

A "hothouse". In 1978 the English playwright Harold Pinter, who was to become the 2005 Nobel laureate in Literature, wrote a play under the title The Hothouse. He set it aside until one day in 1979, when having re-read it he directed its first production at the Hampstead Theater in London, where it opened on 24 April 1980.The Hothouse is set in an institution whose nature is subject to interpretation: is it a "rest home"? maybe it is a "sanatorium" whose "residents" or "patients" are designated anonymously by numbers, not by their names [3].

This description fits rather well with Joseph Fourier's hothouse concept, because, by Arrhenius's reckoning, Fourier's hot house" lets through the light rays of the sun but retains the dark rays from the ground”. [By "dark rays" understand "infrared light" by today's standards].

Thus was born surreptitiously the modern assertion concerning gases said to produce the Fourier "Hothouse effect”- the Greenhouse Effect in English, l'Effet de serre in French, 温室 in Chinese, оранжерея in Russian, efectoinvernadero in Spanish...

Read casually, the question Svante Arrhenius raised seems to be both pertinent and... innocent. Well, let us have the inquisitive mind of some famous detective, perhaps Sir Arthur Conan Doyle's Sherlock Holmes or better, why not, Earl Derr Biggers' Charlie Chan (Figure 2). Then the expression "heat-absorbing gases” that Arr-

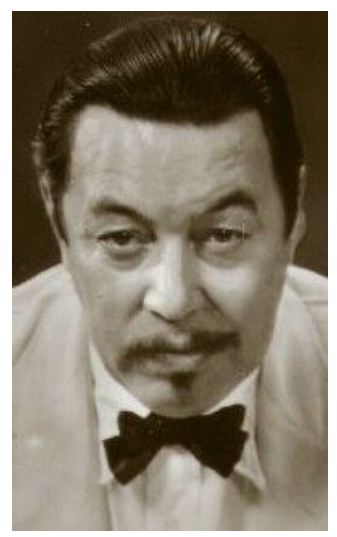

Figure 2. An inquisitive mind: Charlie Chan. https://upload.wikimedia.org/wikipedia/en/a/ad/Warner_Oland.jpg. 
henius uses in his question would, at least, intrigue us. We would read the paper further in the hope that Arrhenius will clarify its (hidden) meaning. Indeed he explains: "The air retains heat (light or dark) in two different ways.”

Oh, oh! Heat is either light or dark—in brief Heat is perhaps not unlike our contemporary Energy which some physicists say is either "ordinary" or "dark" [2].

\section{Absorb?}

Let us pursue. Arrhenius writes: "On the one hand, the heat suffers a selective diffusion on its passage through the air; on the other hand"-and this is the all-important statement- "some of the atmospheric gases absorb considerable quantities of heat [our emphasis]."

Absorb considerable quantities of heat... Here we are. The verdict falls: "The selective absorption is [exerted] to a high degree by aqueous vapour and carbonic acid."

"Aqueous vapour [British spelling]" and "carbonic acid”... Arrhenius does not speak openly of "carbon dioxide" $\left(\mathrm{CO}_{2}\right)$, but his devoted followers have discreetly corrected the mismatch. A century later, Climate experts established an Index which measures the "Global Land-Ocean Temperature change" over a period going back to the 1951-1980 mean taken to be 0 . They report an increase of about $0.6^{\circ} \mathrm{C}$ during the period $1980-2013$ and predict that the change will accelerate from hereon with disastrous effects for life on Earth [4]. Other experts, working for the International Panel on Climate Change (IPCC), asserted in 2014 that they were "more than 95\% certain" [our emphasis] that most of the global warming is caused by increasing concentrations of "greenhouse gases" and other "human (anthropogenic) activities", asserting: "Anthropogenic greenhouse gas emissions have increased since the pre-industrial era, driven largely by economic and population growth, and are now higher than ever" a statement one would be hard-pressed to dispute. To which they added, however: "This has led to atmospheric concentrations of carbondioxide [here we are!], methane and nitrous oxide that are unprecedented in at least the last 800,000 years". And they concluded forcefully: "Their effects, together with those of other anthropogenic drivers, have been detected throughout the climate system and are extremely likely [our emphasis] to have been the dominant cause of the observed warming since the mid-20th century".

Extremely likely, therefore "not absolutely certain”. Fortunately Quantum Physics (QP) comes to the rescue.

\section{Inside the Hothouse Confined Space}

Let us return to Arrhenius' assertion that, according to Joseph Fourier, the atmosphere "acts like the glass of a hot-house...”

The greenhouses of our gardens traditionally have a roof constructed with ordinary glass, a material which has a particularity: transparent to visible light, it is opaque to infrared rays (heat) radiated by the plants and the objects placed in the greenhouse's confine. A glass roof thus prevents the heat accumulated in the confine from exiting to the outside - this is the whole point of having a greenhouse, the converse in brief of a refrigerator constructed to prevent heat from entering in the confined space.

What about the atmosphere?

Svante Arrhenius and his modern followers want us to believe that "aqueous vapors”, whatever they might be, and "carbonic acid" play in the atmosphere the same role as the glass roof plays in garden greenhouses.

In reality this is an artifice of language, as we now demonstrate.

\section{Quantum Swifts}

Swifts-martinets in French, стрижи in Russian, 雨燕 in Chinese, vencejos in Spanish...-are spectacular birds that one can see crisscrossing the skies in quest of food (aerial plankton) at certain times of the year in many countries around the world (Figure 3). The Earth's atmosphere is some kind of a "sky" crisscrossed by what one might call "quantum swifts"-gas molecules. Indeed, even though collectively they form a gas, the molecules present in the atmosphere move freely and individually in ordinary conditions of air pressure and temperatures just as swifts do when they crisscross the skies. Call these molecules Quantum Swifts (QS). Then the fundamental point is this: QS do NOT form in the atmosphere a structure which could by any stress of the imagination be assimilated to something resembling in any way or form the glass roof of a hothouse - of a greenhouse if you prefer. 


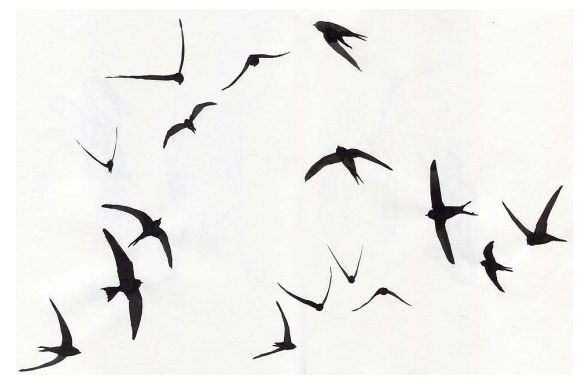

Figure 3. Swifts in flight.

http://1.bp.blogspot.com/-7zSLRsh2YaY/TijxPilqH4I/AAAAAAAABYs/lSHh6vedFLc/s1600/bunchosketches.jpg.

There is more. Physics teachers in schools or universities around the world commonly tell their students that perpetual motion on Earth "is impossible". They would be well advised to add: "Perpetual motion in the quantum world is the rule". We explore the highly significant consequences of this fact.

\section{Quantum Perpetual Motion}

Dry air in the atmosphere contains about 79\% nitrogen molecules $\left(\mathrm{N}_{2}\right)$, 21\% oxygen molecules $\left(\mathrm{O}_{2}\right)$ and $1 \%$ argon atoms (A) by volume. The Earth's atmosphere also hosts a complex of ingredients containing water molecules $\left(\mathrm{H}_{2} \mathrm{O}\right)$ - water vapor, clouds, rain drops, ice crystals, snow...-plus a modest average $0.03 \%-0.04 \% \mathrm{CO}_{2}$ molecules. When submitted to ordinary conditions of temperature and pressure, the molecules present in the atmosphere- $\mathrm{N}_{2}, \mathrm{O}_{2}, \mathrm{H}_{2} \mathrm{O}, \mathrm{CO}_{2}$ and the others-not only crisscross the atmosphere continuously like quantum swifts, but they are also individually kept by quantum laws of Nature in a perpetual state of internal vibrational (and rotational) motion. Our ordinary swifts crisscrossing the skies are too in a perpetual state of motion, flapping their wings to move about swiftly. The difference is that flying swifts have full control of their motions: they can flap their wings at any speed they wish, or stop flapping and glide. By contrast, the vibrational-rotational agitation which animates our "quantum swifts" cannot be stopped nor modulated. This motion is a permanent feature of the molecules concerned-they are in a state of individual quantum perpetual agitation.

In their days, neither Fourier nor Arrhenius nor any of the other pioneers in this field were aware of this state of affairs. It can be shown-but we shall not attempt to do so in this note- that it is in this direction that one must look for an interaction between vibrating "quantum swifts” and outgoing IR rays emanated from the Earth's surfaces. And the result of such an analysis confirms that the infamous $\mathrm{CO}_{2}$ molecules are in no way involved in generating a significant "Greenhouse Effect" in the atmosphere.

\section{By the Way...}

By the way, composed of three atoms - one carbon and two oxygen atoms - the $\mathrm{CO}_{2}$ molecules are just about the heaviest molecules present in the atmosphere. As a result, they tend to accumulate in the atmosphere's layers close to the ground - or close to the surface of the oceans-for the great pleasure of our trees which "breathe" carbon dioxide through the pores of their green leaves - a mechanism one might want to call the "Green Leaves Effect”.

\section{Conclusions}

The president of the French Republic, Mr François Hollande, will be greeting international delegates convening in Paris-Le Bourget from November 30 to December 11 to partake in the 2015 "United Nations Climate Change Conference", also known as "COP21" and "CMP11" reflecting the facts that it will be the 21st yearly session of the "Conference of the Parties to the 1992 United Nations Framework Convention on Climate Change" (UNFCCC) and the 11th session of the "Meeting of the Parties to the 1997 Kyoto Protocol”. The conference objective is officially "to achieve a legally binding and universal agreement on climate from all the nations of the world". Leadership of the negotiations is yet to be determined.

The delegates to this Conference might wish to consider the possibility that the designation "Green House Gas” be declared to be inappropriate when applied to atmospheric carbon dioxide and be officially banished from use with this meaning in climate reports. Else, a fallacy will be perpetuated一谬论仍将会延续下去 in 
Chinese.

\section{Acknowledgements}

We are indebted to Ms. Clara Gao, to Ms. Kelly Sang, to Ms. Freya Zhang and to Ms. Angela Zhang, JMP Editorial Board Assistants, for their valuable help and advice in properly preparing this paper for publication online in this journal.

\section{References}

[1] Arrhenius, S. (1896) Philosophical Magazine and Journal of Science Series 5, 41, 237-276. http://www.rsc.org/images/Arrhenius1896_tcm18-173546.pdf

[2] Auffray, J.-P. (2015) Journal of Modern Physics, 6, 1478-1491. http://dx.doi.org/10.4236/jmp.2015.611152

[3] Pinter, H. (1980) The Hothouse: A Play by Harold Pinter. Grove Press, New York. https://en.wikipedia.org/wiki/The_Hothouse

[4] Climate Change 2014 Synthesis Report Summary for Policymakers. https://www.ipcc.ch/pdf/assessment-report/ar5/syr/AR5 SYR FINAL SPM.pdf 